\title{
An investigation of the role of human resource management on enterprise resource planning
}

\author{
Samiyeh Bandad and Somayeh Hozouri*
}

Department of Management, Islamic Azad University, South Tehran Branch, Tehran, Iran

\begin{tabular}{|c|c|}
\hline CHRON I C LE & A B S T RACT \\
\hline $\begin{array}{l}\text { Article history: } \\
\text { Received June } 10,2013 \\
\text { Received in revised format } \\
25 \text { August } 2013 \\
\text { Accepted September } 262013 \\
\text { Available online } \\
\text { October } 142013 \\
\text { Kevwords: }\end{array}$ & $\begin{array}{l}\text { This paper presents an investigation on the role of human resource management on enterprise } \\
\text { resource planning in one of higher educational systems in city of Tehran, Iran. The proposed study } \\
\text { designs a questionnaire in Likert scale consists of } 30 \text { questions, distributes it among some Iranian } \\
\text { experts and analyzes it based on principal component analysis. During the survey, the number of } \\
\text { questions is reduced to } 20 \text {. Cronbach alpha is calculated as } 0.86 \text { and Kaiser-Meyer-Olkin Measure of } \\
\text { Sampling Adequacy and Approx. Chi-Square are } 0.716 \text { and } 1169 \text {, respectively. Based on the results } \\
\text { of our survey, we have derived five factors including environment analysis, infrastructure } \\
\text { components, managerial decisions, integrated information systems and control components. }\end{array}$ \\
\hline
\end{tabular}

Factor analysis

Human resource management

\section{Introduction}

Enterprise resource planning (ERP) is one of the most important issues, which could create improvement on organizational efficiency (Oztemel et al., 2011; Azevedo et al., 2012). However, many ERP implementations may fail because of lack of support from human resources within organizations. There are literally various studies associated with ERP implementation. Boltena and Gomez (2012), for instance, presented a case study of an ERP system implementation by a medium company in Ethiopia named Mesfine Industrial Engineering (MIE) Pvt. Ltd., which has recently adopted and implemented an ERP system. They examined key dimensions of implementation of ERP system within MIE and performed an in-depth investigation at the issues behind the process of ERP implementation by concentrating on business and technical as well as cultural issues. The case study also looked at the implementation risks and reported how MIE had coped with the typical challenges that most medium organizations faced when implementing an ERP system. Pacheco-Comer and González-Castolo (2012) reported there was a relationship between size of the company and the amount of investment.

* Corresponding author. Tel.: +989125367924

E-mail addresses: saho84@rocketmail.com (S. Hozouri)

(C) 2014 Growing Science Ltd. All rights reserved. doi: $10.5267 /$ j.uscm.2013.10.001 
Asl et al. (2012) identified and ranked the important factors influencing on selecting ERP system using the combined Delphi and Shannon Entropy approach. They identified the most important criteria of ERP selection that organizations should consider in the process of their selection, through a comprehensive investigation on the past literature and researches and including the exports' viewpoints. They detected different factors including cost, software quality, vendor and software capability as the main factors, which should be considered by the organizations.

Rouhani and Ravasan (2013) stated that achieving a proper level of ERP success depends on different factors associated with an organization or project environment and they discussed the idea of forecasting ERP post-implementation success based on organizational profiles. They developed an expert system by exploiting the Artificial Neural Network (ANN) technique to articulate the relationships between some organizational factors and ERP success. Azad et al. (2013) presented an empirical investigation to find important factors influencing ERP implementation in one of the biggest Iranian automakers named Iran Khodro. They derived eight factors including intelligence information, customer comfort, structure oriented, resource management, process oriented, customer oriented, flexible structure and knowledge management. Karande and Chakraborty (2012) solved two ERP system selection problems using fuzzy multi-objective optimization on the basis of ratio analysis (MOORA) method and it was observed that in both the cases, SAP (Khoury et al., 2012) was the best solution.

\section{The proposed study}

This paper presents an investigation on the role of human resource management on enterprise resource planning in one of higher educational systems in city of Tehran, Iran. The proposed study designs a questionnaire in Likert scale consists of 30 questions, distributes it among some Iranian experts and analyzes it based on principal component analysis. During the survey, the number questions are reduced to 20. Cronbach alpha is calculated as 0.86 and Kaiser-Meyer-Olkin Measure of Sampling Adequacy and Approx. Chi-Square are 0.716 and 1169 , respectively. Fig. 1 demonstrates the results of Scree plot.

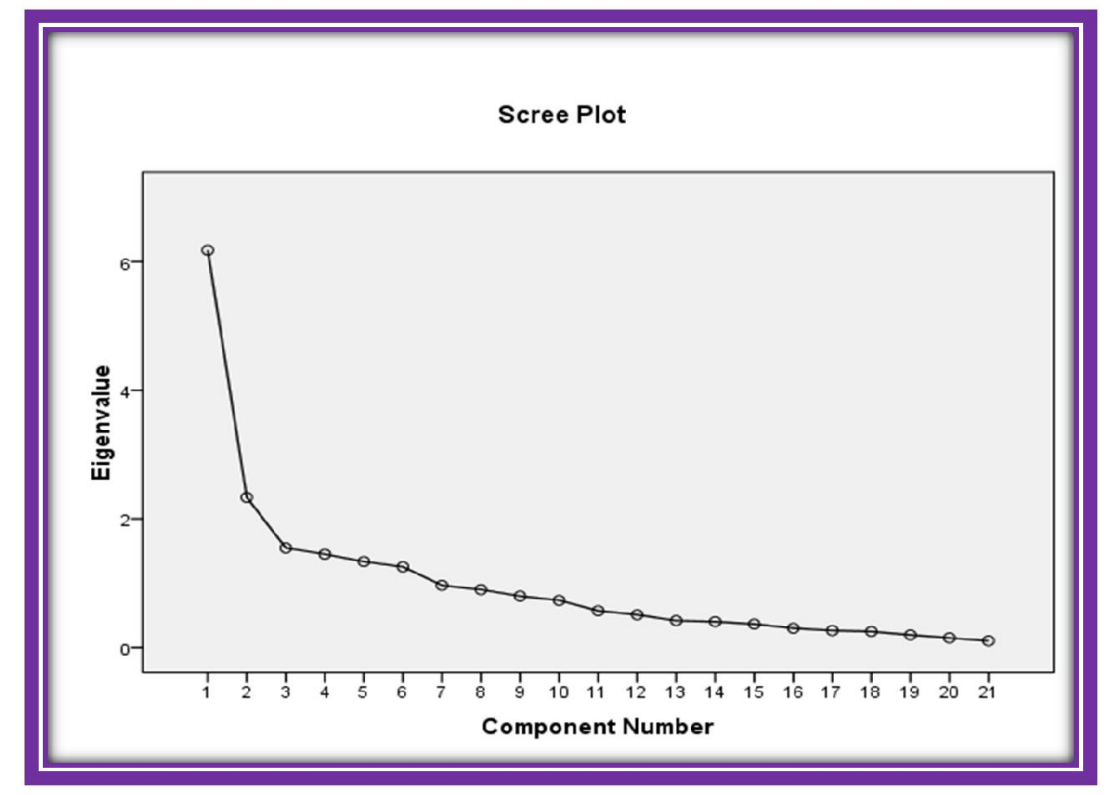

Fig. 1. The summary of Scree plot 
As we can observe from the results of Fig. 1, there are five factors, which could be extracted for further studies. In addition, as we can observe from the results of communalities given in Table 1, most factors are well above the minimum acceptable level of 0.5 . Table 2 demonstrates the results of factor analysis on these factors.

Table 1

The summary of communalities

\begin{tabular}{ccc}
\hline & Communalities & Extraction \\
\hline VAR00002 & Initial & .654 \\
VAR00003 & 1.000 & .787 \\
VAR00005 & 1.000 & .701 \\
\hline VAR00006 & 1.000 & .585 \\
\hline VAR00009 & 1.000 & .481 \\
\hline VAR00013 & 1.000 & .657 \\
\hline VAR00014 & 1.000 & .628 \\
\hline VAR00015 & 1.000 & .764 \\
\hline VAR00016 & 1.000 & .798 \\
\hline VAR00017 & 1.000 & .783 \\
\hline VAR00018 & 1.000 & .710 \\
\hline VAR00019 & 1.000 & .492 \\
\hline VAR00020 & 1.000 & .738 \\
\hline VAR00021 & 1.000 & .715 \\
\hline VAR00024 & 1.000 & .654 \\
\hline VAR00025 & 1.000 & .698 \\
\hline VAR00026 & 1.000 & .742 \\
\hline VAR00027 & 1.000 & .713 \\
\hline VAR00029 & 1.000 & .499 \\
\hline
\end{tabular}

Table 2

The summary of principal component analysis after rotation

\begin{tabular}{|c|c|c|c|c|c|c|c|c|c|}
\hline \multirow{3}{*}{ Component } & \multicolumn{6}{|c|}{ Total Variance Explained } & \multirow{2}{*}{\multicolumn{3}{|c|}{ Rotation Sums of Squared Loadings }} \\
\hline & \multirow[b]{2}{*}{ Total } & \multirow{2}{*}{$\begin{array}{l}\text { Initial Eigenvalues } \\
\% \text { of Variance }\end{array}$} & \multirow[b]{2}{*}{$\begin{array}{c}\text { Cumulative } \\
\%\end{array}$} & \multicolumn{3}{|c|}{ Extraction Sums of Squared Loadings } & & & \\
\hline & & & & Total & $\begin{array}{c}\% \text { of } \\
\text { Variance }\end{array}$ & $\begin{array}{c}\text { Cumulative } \\
\%\end{array}$ & Total & $\begin{array}{r}\% \text { of } \\
\text { Variance }\end{array}$ & $\begin{array}{r}\text { Cumulative } \\
\%\end{array}$ \\
\hline 1 & 6.178 & 29.419 & 29.419 & 6.178 & 29.419 & 29.419 & 3.338 & 15.894 & 15.894 \\
\hline 2 & 2.333 & 11.109 & 40.528 & 2.333 & 11.109 & 40.528 & 2.751 & 13.098 & 28.992 \\
\hline 3 & 1.547 & 7.367 & 47.895 & 1.547 & 7.367 & 47.895 & 2.380 & 11.334 & 40.326 \\
\hline 4 & 1.450 & 6.906 & 54.802 & 1.450 & 6.906 & 54.802 & 2.282 & 10.868 & 51.194 \\
\hline 5 & 1.335 & 6.359 & 61.161 & 1.335 & 6.359 & 61.161 & 1.924 & 9.163 & 60.357 \\
\hline 6 & 1.253 & 5.968 & 67.129 & 1.253 & 5.968 & 67.129 & 1.422 & 6.771 & 67.129 \\
\hline 7 & .966 & 4.599 & 71.727 & & & & & & \\
\hline 8 & .899 & 4.281 & 76.008 & & & & & & \\
\hline 9 & .797 & 3.797 & 79.806 & & & & & & \\
\hline 10 & .732 & 3.485 & 83.291 & & & & & & \\
\hline 11 & .569 & 2.712 & 86.002 & & & & & & \\
\hline 12 & .508 & 2.420 & 88.422 & & & & & & \\
\hline 13 & .416 & 1.982 & 90.404 & & & & & & \\
\hline 14 & .400 & 1.907 & 92.310 & & & & & & \\
\hline 15 & .363 & 1.727 & 94.037 & & & & & & \\
\hline 16 & .299 & 1.423 & 95.460 & & & & & & \\
\hline 17 & .263 & 1.253 & 96.713 & & & & & & \\
\hline 18 & .247 & 1.177 & 97.890 & & & & & & \\
\hline 19 & .194 & .923 & 98.813 & & & & & & \\
\hline 20 & .147 & .701 & 99.514 & & & & & & \\
\hline 21 & .102 & .486 & 100.000 & & & & & & \\
\hline
\end{tabular}

Based on the results of our survey, we have derived five factors including environment analysis, infrastructure components, managerial decisions, integrated information systems and control components. 


\section{The results}

In this section, we present details of our findings on five influencing factors.

\subsection{The first factor: Environment analysis}

The first factor is associated with environment analysis. Table 3 demonstrates details of our study. As we can observe from the results of Table 3, "Facilitating the flow of information" is the most important factor, followed by "Having completely automated systems".

Table 3

The summary of factors associated with environment analysis

\begin{tabular}{llccc}
\hline Option & Factor weight & Eigenvalues & \% of variance & Accumulated \\
\hline Having completely automated systems & .775 & & & \\
Facilitating the flow of information & .803 & 2.489 & 62.223 & 62.223 \\
\hline
\end{tabular}

Cronbach alpha $=0.82$

\subsection{The second factor: Infrastructure components}

Infrastructure components are the second important factors and they include three factors, which are summarized in Table 4 as follows,

\section{Table 4}

The summary of factors associated with infrastructure components

\begin{tabular}{lllll}
\hline \multicolumn{1}{c}{ Option } & Factor weight & eigenvalues & \% of variance & Accumulated \\
\hline Completion times of projects & .728 & & & 50.767 \\
Organization budget & .746 & 2.031 & 50.767 & \\
Upgrade as the primary objective & .726 & & & \\
\hline Cronbach alpha $=0.69$ & & &
\end{tabular}

According to the results of Table 4, "organization budget" is number one priority followed by "completion times of projects" and "Upgrade as the primary objective of organization".

\subsection{The third factor: Managerial decisions}

Managerial decisions other important factors with five items summarized in Table 5.

\section{Table 5}

The summary of factors associated with managerial decisions

\begin{tabular}{llccc}
\hline Option & Factor weight & eigenvalues & \% of variance & Accumulated \\
\hline Providing solutions & .853 & & & 69.762 \\
Management skills improvement & .863 & 2.093 & 69.762 & \\
Resources & .753 & & & \\
\hline Analysis of responses & .813 & & \\
\hline Actual times of project completions & .846 & & \\
\hline Cronbach alpha $=0.738$ & & & &
\end{tabular}

According to the results of Table 5, "Management skills improvement" is the most important component in organizational assessment followed by "Providing solutions", "Actual times of project completions", "Analysis of responses" and "Resources". 


\subsection{The fourth factor: Integrated information system}

Integration information system is another important factor with four items summarized in Table 6. According to the results of Table 6, "Administration and support systems" is the most important component in organizational assessment followed by "Databases", "Quality of supporting systems" and "Recording information".

Table 6

The summary of factors associated with integrated information system

\begin{tabular}{lcccc}
\hline \multicolumn{1}{c}{ Option } & Factor weight & eigenvalues & \% of variance & Accumulated \\
\hline Databases & .853 & & & 70.784 \\
Administration and support systems & .863 & 2.153 & 70.784 \\
Recording information & .751 & & & \\
Quality of supporting systems & .823 & & & \\
\hline Cronbach alpha $=0.79$ & & &
\end{tabular}

\subsection{The fifth factor: Control components}

Communication strategy is another important factor with two items summarized in Table 7. According to the results of Table 7, "Hierarchy structure" is the most important component in control components followed by "Reducing costs".

\section{Table 7}

The summary of factors associated with organizational development

\begin{tabular}{lcccc}
\hline \multicolumn{1}{c}{ Option } & Factor weight & eigenvalues & \% of variance & Accumulated \\
\hline Reducing costs & .853 & & & \\
Hierarchy structure & .863 & 3.093 & 80.789 & 80.789 \\
\hline Cronbach alpha $=0.79$ & & &
\end{tabular}

\section{Conclusion}

This paper has presented an investigation on the role of human resource management on enterprise resource planning in one of higher educational systems in city of Tehran, Iran and the study has determined five factors including environment analysis, infrastructure components, managerial decisions, integrated information systems and control components. The first factor was associated with environment analysis where "Facilitating the flow of information" was the most important factor, followed by "Having completely automated systems". Infrastructure components are the second important factors and they include three factors where "organization budget" was number one priority followed by "completion times of projects" and "Upgrade as the primary objective of organization". Managerial decisions other important factors with five items where "Management skills improvement" is the most important component in organizational assessment followed by "Providing solutions", "Actual times of project completions", "Analysis of responses" and "Resources". Integration information system is another important factor with four items where "Administration and support systems" is the most important component in organizational assessment followed by "Databases", "Quality of supporting systems" and "Recording information". Finally, communication strategy was the important factor with two items where "Hierarchy structure" is the most important component in control components followed by "Reducing costs".

\section{Acknowledgment}

The authors would like to thank the anonymous referees for their construction comments on earlier version of this work. 


\section{References}

Asl, M. B., Khalilzadeh, A., Youshanlouei, H. R., \& Mood, M. M. (2012). Identifying and ranking the effective factors on selecting Enterprise Resource Planning (ERP) system using the combined Delphi and Shannon Entropy approach. Procedia-Social and Behavioral Sciences, 41, 513-520.

Azad, N., Shadmanfard, A., \& Zarifi, S.F. (2013). An exploration study to find important factors influencing on enterprise resource planning. Management Science Letters, 3(9), 2405-2410.

Azevedo, P. S., Romão, M., \& Rebelo, E. (2012). Advantages, limitations and solutions in the use of ERP systems (Enterprise Resource Planning)-A case study in the hospitality industry. Procedia Technology, 5, 264-272.

Boltena, A. S., \& Gomez, J. M. (2012). A successful ERP implementation in an Ethiopian company: A case study of ERP implementation in Mesfine industrial engineering Pvt. Ltd. Procedia Technology, 5, 40-49.

Karande, P., \& Chakraborty, S. (2012). A Fuzzy-MOORA approach for ERP system selection. Decision Science Letters, 1(1), 11-21.

Khoury, S., Jenab, K., \& Staub, S. (2012). Faculty perceptions of the integration of SAP in academic programs. Management Science Letters, 2(4), 1047-1052.

Oztemel, E., Arslankaya, S., \& KorkusuzPolat, T. (2011). Enterprise knowledge management model (EKMM) in strategic enterprise resource management (SERM). Procedia-Social and Behavioral Sciences, 24, 870-879.

Pacheco-Comer, A. A., \& González-Castolo, J. C. (2012). An empirical study in selecting Enterprise Resource Planning Systems: The relation between some of the variables involve on it. Size and Investment. Procedia Technology, 3, 292-303.

Rouhani, S., \& Ravasan, A. Z. (2013). ERP success prediction: An artificial neural network approach. Scientia Iranica, 20(3), 992-1001. 